\title{
Fibrose cística: uma abordagem clínica e nutricional
}

\author{
Cystic fibrosis: a clinical and \\ nutritional approach
}

\author{
Fernanda Ribeiro ROSA ${ }^{1}$ \\ Fernanda Gomes DIAS ${ }^{1}$ \\ Luciana Neri NOBRE ${ }^{1}$ \\ Harriman Aley MORAIS²
}

\section{RE S U M O}

A fibrose cística é a doença genética letal mais comum em populações caucasianas e é caracterizada por infecções crônicas e recorrentes do pulmão, insuficiência pancreática e elevados níveis de cloro no suor. É uma doença de herança autossômica recessiva causada pela mutação no gene do Regulador da Condutância Transmembrana da Fibrose Cística, que induz o organismo a produzir secreções espessas e viscosas que obstruem os pulmões, o pâncreas e o ducto biliar. Muitos pacientes apresentam insuficiência pancreática, que leva a má-absorção de nutrientes especialmente de proteínas e lipídeos e a complicações gastrintestinais tais como prolapso retal, síndrome da obstrução intestinal, constipação e cirrose hepática. A fibrose cística normalmente é diagnosticada na infância, pelos programas de triagem neonatal ou pelo teste do suor. Devido aos vários sistemas envolvidos e à variabilidade e cronicidade da doença, uma abordagem multidisciplinar é essencial para auxiliar o paciente e sua família a compreenderem a doença e aderirem ao tratamento. A terapia atual da fibrose cística inclui a manutenção do estado nutricional, a remoção das secreções das vias aéreas com fisioterapia e mucolíticos, o uso de antibióticos para prevenção e tratamento de infecções, a prescrição de suplementos energéticos, dietas hiperlípidicas e hiperprotéicas, bem como a suplementação de minerais e vitaminas lipossolúveis. O objetivo deste trabalho foi realizar breve revisão de literatura sobre os aspectos clínicos e nutricionais da fibrose cística.

Termos de indexação: Desnutrição. Fibrose cística. Terapia nutricional.

\section{A B S T R A C T}

Cystic fibrosis is the most common, lethal, genetic disease in Caucasian populations and is characterized by chronic and recurrent lung infections, pancreatic insufficiency and high sweat chloride levels. It is an autosomal

\footnotetext{
1 Universidade Federal dos Vales do Jequitinhonha e Mucuri, Faculdade de Ciências Biológicas e da Saúde, Departamento de Nutrição. Diamantina, MG, Brasil.

2 Universidade Federal dos Vales do Jequitinhonha e Mucuri, Faculdade de Ciências Biológicas e da Saúde, Departamento de Ciências Básicas. R. da Glória, 187, Centro, 39100-000, Diamantina, MG, Brasil. Correspondência para/Correspondence to: H. A. MORAIS. E-mail: <hamorais@gmail.com>.
} 
recessive hereditary disease caused by a mutation in the cystic fibrosis transmembrane conductance regulator gene which induces the body to produce thick and viscous mucus secretions that obstruct the lungs, pancreas and bile duct. Many patients have pancreatic insufficiency which leads to malabsorption of nutrients, especially proteins and fats and to gastrointestinal complications such as rectal prolapse, intestinal obstruction syndrome, constipation and hepatic cirrhosis. Cystic fibrosis is usually diagnosed during childhood by neonatal screening programs or sweat test. Because of the multiple systems involved and the variability and chronicity of the disease, a multidisciplinary team is essential to help patients and their families understand the disease and adhere to treatment. Current cystic fibrosis therapy includes maintaining the nutritional status, clearing the airways with physiotherapy and mucolytics, preventing and treating infections with antibiotics and prescribing energy supplements, high-fat and high-protein diets, as well as minerals and fat-soluble vitamins. The purpose of this study was to present a brief literature review of the clinical and nutritional aspects of cystic fibrosis.

Indexing terms: Malnutrition. Cystic fibrosis. Nutrition therapy.

\section{N T R O D U Ç Ã O}

Nos últimos 70 anos, a fibrose cística foi reconhecida como a mais importante doença hereditária, potencialmente letal. O gene da fibrose cística foi identificado, clonado e seqüenciado, favorecendo o conhecimento dos mecanismos bioquímicos responsáveis pela fisiopatogenia da doença, possibilitando o aconselhamento genético e o tratamento de suas complicações. Esta foi uma das doenças que mais mobilizou os familiares de forma tão organizada, a ponto de constituírem associações de pais na Europa, nas Américas e, inclusive, no Brasil, desempenhando um importante papel no tratamento da fibrose cística ${ }^{1}$.

A fibrose cística, ou mucoviscidose, é uma doença genética de caráter autossômico recessivo, crônica e progressiva, que atinge vários órgãos e sistemas do organismo. É comum na raça branca e atinge igualmente ambos os sexos. O paciente portador dessa doença apresenta secreções mucosas espessas e viscosas, obstruindo os ductos das glândulas exócrinas, que contribuem para o aparecimento de três características básicas: doença pulmonar obstrutiva crônica, níveis elevados de eletrólitos no suor, insuficiência pancreática com má digestão/má absorção e conseqüente desnutrição secundária².

A importância do estado nutricional para aumento da sobrevida e bem-estar dos pacientes com fibrose cística é bem documentada na literatura. No entanto, a desnutrição continua sendo um sério problema para os pacientes com fibrose cística. Nos Estados Unidos, o peso e a estatura de cerca de $20 \%$ das crianças e adolescentes com fibrose cística estão abaixo do percentil 5. Dados a respeito da população com fibrose cística no Reino Unido (UK) também mostram déficits de peso e estatura, principalmente na faixa etária entre 1 e 10 anos de idade, embora tenha havido uma melhora no estado nutricional desses pacientes com relação às décadas anteriores ${ }^{3}$. A magnitude desse problema pode ser mais grave em países subdesenvolvidos, visto que pode haver uma sobreposição de desnutrição primária e secundária na população com fibrose cística4 ${ }^{4}$.

A educação alimentar destinada a pacientes com fibrose cística e familiares, envolvendo informação nutricional, uso correto de enzimas, recomendações reforçadas de uma alimentação adequada e uso de suplementos hiperenergéticos, quando indicado, pode assegurar que os pacientes recebam um ótimo tratamento nutricional e uma melhora na qualidade de vida ${ }^{4}$.

Frente a esses aspectos, o objetivo deste trabalho foi realizar uma breve revisão de literatura sobre os aspectos clínicos e nutricionais da fibrose cística.

\section{Aspectos bioquímicos e moleculares}

O gene da fibrose cística localiza-se no braço longo do cromossomo 7, no lócus q31, e é formado por 250 quilobases de DNA, com 27 éxons, e tem a propriedade de codificar um RNAm de 6,5 quilobases, que transcreve uma proteína 
transmembrana, reguladora de transporte iônico, composta por 1480 aminoácidos, conhecida como Cystic Fibrosis Transmembrane Conductance Regulator (CFTR- Regulador da Condutância da Transmembrana da Fibrose Cística). Também chamada de canal de cloro, esta proteína é sintetizada no núcleo, sofre maturação em organelas citoplasmáticas (fosforilação e glicosilação), localizando-se na membrana apical das células. A CFTR é essencial para o transporte de íons através da membrana celular, estando envolvida na regulação do fluxo de cloro $(\mathrm{Cl})$, sódio $(\mathrm{Na})$ e água 5 .

De todas as mutações no gene CFTR, a mais freqüente é a mutação $\Delta \mathrm{F} 508$, uma deleção de um códon para a fenilalanina na posição 508 da proteína. Este mutante está presente em, aproximadamente, $70 \%-80 \%$ dos cromossomos de fibrocísticos brancos europeus ${ }^{6}$. Entretanto, a freqüência relativa da mutação $\Delta \mathrm{F} 508$ tem uma variabilidade muito grande entre diferentes regiões geográficas e distintos grupos étnicos. No Brasil foi encontrada a freqüência média de $47 \%{ }^{7}$; sendo 49\% no Rio Grande do Sul, 27\% em Santa Catarina, 52\% em São Paulo ${ }^{8}$, 53\% em Minas Gerais e $44 \%$ no Paraná7.

Em um estudo no Sul do País foram encontradas freqüência semelhante a da população italiana para duas mutações raras da fibrose cística, R1162X e 2183AA $\rightarrow G$, o que foi explicado devido à grande migração desses povos para essa região do Brasil7.

\section{Aspectos epidemiológicos}

Uma em cada 25 pessoas da população traz consigo o gene defeituoso, que é expresso quando uma criança herda o gene RTFC defeituoso de ambos os genitores. Este fato é compatível com uma freqüência observada de, aproximadamente, 1 em cada 2500 nascidos-vivos ${ }^{9}$.

A prevalência da fibrose cística varia de acordo com a etnia, de $1 / 2000$ até $1 / 5$ mil caucasianos nascidos-vivos na Europa, nos Estados
Unidos e no Canadá, 1/15 mil negros americanos, e 1/40 mil na Finlândia ${ }^{5}$, sendo considerada rara em asiáticos e africanos ${ }^{10}$.

No Brasil, a prevalência estimada para a região Sul é mais próxima da população caucasiana centro-européia, decrescendo em direção a região Sudeste e Norte do País ${ }^{11}$. Porém, não há estudos epidemiológicos ou de triagem neonatal abrangentes que permitam estimar a incidência da doença no País, pois menos de $10 \%$ do total anual de casos são diagnosticados ${ }^{12}$. Apesar da inexistência de dados fidedignos sobre a incidência/prevalência de fibrose cística no Brasil, segundo a portaria $n^{\circ} 338$ de 29 de junho de $2005^{13}$, há no País, aproximadamente, 2 mil portadores de fibrose cística.

Entre 1930 e 1940, quando a fibrose cística foi identificada e descrita pela primeira vez, a sobrevida acima dos cinco anos era muito rara. Era considerada uma doença da infância, com $80 \%$ das crianças afetadas morrendo no primeiro ano de vida ${ }^{14}$. Os avanços no diagnóstico e as estratégias terapêuticas desenvolvidas nos últimos 30 anos têm elevado a expectativa de vida dos pacientes com fibrose cística, mas, ainda assim, $15 \%$ a $20 \%$ das crianças com fibrose cística morrem antes de seu décimo ano de vida ${ }^{15}$. Nos últimos anos tem-se conseguido aumentar a esperança de vida dessas pessoas, no entanto, é difícil a sobrevivência após os 30 anos. De um modo geral, os pacientes tratados em centros de Fibrose Cística, por equipes treinadas em atender, dar seguimento e prevenir complicações, têm melhor prognóstico. Observa-se também uma melhoria quando o diagnóstico e o tratamento são precoces, antes dos danos pulmonares ${ }^{16}$.

De acordo Reis et al. ${ }^{15}$, muitos autores estimam uma sobrevida em torno de 25 a 30 anos. Para alcançar essa sobrevida, o diagnóstico deve ser o mais precoce possível, devendo o tratamento, desde cedo, ser conduzido por profissionais devidamente treinados. Outros fatores também podem influenciar as taxas de sobrevida desses pacientes, quais sejam: melhor suporte nutricional; terapia antibiótica precoce e mais agressiva; 
desenvolvimento de centro de referência para diagnóstico e tratamento da doença cujo objetivo principal é a melhoria na qualidade de vida desses pacientes, além da existência de suporte médico e promoção da educação dos pacientes e suas famílias.

Os maiores índices de sobrevida, em 1989, foram observados nos pacientes dos Estados Unidos (a mediana de sobrevida era de 27 anos) e do Canadá (mediana de sobrevida de 30 anos). Recentes estudos predizem que as crianças com fibrose cística nascidas na década de 90 têm uma expectativa de vida de 40 anos. Na América Latina, esta estimativa é de, aproximadamente, seis anos, utilizando-se a data do diagnóstico e não a data de nascimento como na América do Norte ${ }^{15}$.

Estudos brasileiros mostraram que a média de sobrevida dos pacientes com fibrose cística no período de 1979-1989 era de apenas 6,4 anos, saltando para 12,6 anos no período de 1970-1994. Em outro estudo, desenvolvido na década de 1990-2000, foi observada uma mediana de sobrevida de 18,4 anos de idade após o diagnóstico, estimativa que equivale àquela observada nos Estados Unidos nos anos 8017. Em Minas Gerais, no início da década de 90 , a sobrevida média dos fibrocísticos era de 12,6 anos ${ }^{18}$.

Nos últimos 30 anos, houve aumento marcante na expectativa de vida dos portadores de fibrose cística. Atualmente, a sobrevida de $80 \%$ a $90 \%$ dos pacientes chega a ser superior aos 20 anos de idade, aumentando à medida que precocemente se faz o diagnóstico ${ }^{19}$.

\section{Diagnóstico}

O diagnóstico da fibrose cística se dá pela realização da triagem neonatal, recomendada pelo Ministério da Saúde (MS), empregando-se dosagem da tripsina imunorreativa (IRT). Este teste detecta a tripsina, que está elevada nos fibrocísticos e permanece elevada até 30 dias de idade. $\mathrm{Na}$ presença de alterações no exame, deve-se realizar um segundo, preferencialmente no primeiro mês de vida. Se o segundo também estiver alterado, o diagnóstico é confirmado ou excluído pelo teste do suor, que está alterado em 98\%-99\% dos pacientes ${ }^{20}$.

O método padrão para o teste do suor (TS) consiste na estimulação da produção de suor pela policarpina, que é colocada sobre a pele ou diretamente nas glândulas sudoríparas, usando um gradiente potencial (iontoforese) e análise da concentração dos íons $\mathrm{Na}$ e $\mathrm{Cl}^{20}$. Mesmo sendo considerado um método ouro para o diagnóstico da fibrose cística, é aconselhável realizar outros testes para confirmar a doença, mesmo quando encontrados níveis normais ou limítrofes de níveis de cloro no suor ${ }^{21}$.

Outros testes para diagnóstico da fibrose cística incluem a análise de mutações, teste de alto custo e, no Brasil, são poucos os centros capacitados para realizá-lo; teste da secretina pancreosimina, para quantificar a função pancreática exócrina; dosagem da gordura fecal, usado para avaliar a má digestão e má-absorção de gorduras; detecção de enzimas (quimiotripsina, elastase, lipase imunorreativa) nas fezes; determinação de nitrogênio fecal; detecção sérica de proteína associada à pancreatite; dosagem sérica de triacilgliceróis ${ }^{5}$.

O diagnóstico da fibrose cística também se baseia em achados clínicos clássicos, ou seja, manifestações pulmonares e/ou gastrintestinais típicas, e história de casos da doença na família, confirmado por exames laboratoriais ${ }^{22}$.

\section{Patogenicidade e manifestações clínicas}

A fibrose cística caracteriza-se por uma extensa disfunção das glândulas exócrinas, a qual resulta em um vasto conjunto de manifestações e complicações, tais como, bronquite crônica supurativa com destruição do parênquima pulmonar, insuficiência pancreática (levando à má-absorção e desnutrição), diabetes mellitus, doença hepática e comprometimento do sistema reprodutor masculino e feminino ${ }^{11}$.

Estudos recentes trouxeram aquisições moleculares importantes, que resultaram em 
melhor, embora parcial, conhecimento da patogenia da fibrose cística. Após a identificação do gene da doença, determinou-se que o transporte de íons $\mathrm{Cl}$ e $\mathrm{Na}$ nos tecidos epiteliais, regulado pela proteína CFTR, é defeituoso. A membrana apical das células epiteliais apresenta canais, organizações de moléculas ou parte de moléculas da membrana, dispostas de modo que permitem em resposta a agentes, afetar a permeabilidade da célula. Assim, nas células normais, o canal do cloro, quando estimulado pelo AMPc ou pelo cálcio (Ca) ionóforo, se abre dando saída ao cloro. Na fibrose cística, o canal do cloro não responde ao estímulo do AMPc, somente os canais estimulados pelo Ca ionóforo se abrem, determinando uma diminuição relativa da permeabilidade ao íon cloro. A menor saída de $\mathrm{Cl}$ da célula traz como conseqüência uma maior reabsorção de sódio para manter o equilíbrio $\mathrm{Cl} / \mathrm{Na}$ dentro da célula ${ }^{23}$.

Esse defeito pela limitada secreção de cloro e maior reabsorção de sódio e água traz como resultado alterações nas propriedades físicoquímicas do muco, desidratando-o, tornando-o mais espesso e viscoso, podendo obstruir ductos de vários órgãos afetados ${ }^{23}$.

\section{Manifestações respiratórias}

As complicações respiratórias são as principais causas de mortalidade e morbidade na fibrose cística ${ }^{11}$. O acometimento do aparelho respiratório é progressivo e de intensidade variável, demonstrando queda da função pulmonar ao longo do tempo ${ }^{24}$. O curso clínico é determinado por muco viscoso e clearance mucociliar diminuído, predispondo à sinusite, bronquite, pneumonia, bronquiectasia, fibrose e falência respiratória ${ }^{5}$.

A manifestação mais comum é a tosse crônica persistente, que pode ocorrer desde as primeiras semanas de vida, perturbando o sono e a alimentação do lactente. Muitas crianças apresentam-se com história de bronquiolite de repetição, síndrome do lactente chiador, infecções recorrentes do trato respiratório ou pneumonias recidivantes. Com a evolução da doença, ocorre uma diminuição da tolerância ao exercício. Alguns pacientes são oligossintomáticos por vários anos, o que não impede a progressão silenciosa para bronquiectasias ${ }^{5}$.

A presença de secreções espessas e infectadas leva à obstrução das pequenas vias aéreas e desencadeamento de um processo inflamatório crônico. A inflamação, presente, inclusive, em pulmões anatomicamente normais de recémnascidos, leva à formação de bronquiectasias e lesão pulmonar com progressão, em última instância, para insuficiência respiratória e morte ${ }^{24}$.

A doença pulmonar na fibrose cística caracteriza-se pela colonização e infecção respiratória por bactérias que levam a dano tissular irreversível. Os microorganismos, na maioria das vezes, aparecem nas vias aéreas na seguinte ordem: Staphilococcus aureus, Haemophilus influenzae, Pseudomonas aeruginosa, Pseudomonas aeruginosa mucóide, Pseudomonas cepacea e membros do complexo Burkholderia cepacia ${ }^{5,21,25}$. Nos últimos anos, entretanto, outros microrganismos, especialmente gram-negativos não fermentadores de glicose, vêm sendo apontados como capazes de colonizar a árvore respiratória de portadores de fibrose cística ${ }^{25}$.

O processo infeccioso, por sua vez, aumenta o fenômeno obstrutivo, resultando em um círculo vicioso, difícil de ser interrompido. Embora o processo obstrutivo seja o evento fisiopatológico inicial, a infecção crônica do trato respiratório se apresenta como o evento mais importante, contri-buindo para a piora da função pulmonar e eventual óbito desses pacientes ${ }^{23}$.

\section{Manifestações gastrintestinais}

As manifestações gastrintestinais são, na sua maioria, secundárias à insuficiência pancreática (IP). A obstrução dos canalículos pancreáticos por tampões mucosos impedem a liberação das enzimas para o duodeno, determinando má digestão de gorduras, proteínas e carboidratos ${ }^{26}$. Há também diarréia crônica, com fezes volumo- 
sas, gordurosas, pálidas, de odor característico e, finalmente, desnutrição energético protéica, acentuada por outros fatores inerentes à fibrose cística27.

A má absorção é predominantemente ocasionada pela disfunção pré-epitelial e decorre da rejeição de nutrientes não hidrolisados no lúmen pela insuficiente secreção pancreática. Em 85\% dos pacientes fibrocísticos, o pâncreas não produz enzimas suficientes para completa digestão dos alimentos ingeridos, e uma das primeiras manifestações é a má-absorção de nutrientes ${ }^{11}$. As proteínas requeridas para o crescimento e reparo de tecidos do corpo não são totalmente utilizadas. A gordura, o nutriente mais energético não é absorvido; assim, o crescimento é atrasado e as deficiências de vitaminas lipossolúveis podem ocorrer $^{28}$.

Outra conseqüência desta doença no pâncreas é a diminuição da secreção de bicarbonato de sódio, que evitaria influxos de ácidos gástricos no duodeno, reduzindo a eficácia das enzimas pancreáticas e precipitação de sais biliares $^{29}$. A baixa concentração de bicarbonato no suco pancreático faz com que o $\mathrm{pH}$ do duodeno seja ácido, e isso contribui para a má-absorção ${ }^{11}$.

A primeira manifestação da insuficiência pancreática (IP) na fibrose cística é o íleo meconial (obstrução do íleo terminal por um mecônio espesso), que aparece em 15\%-20\% dos bebês. Porém, a maioria dos diagnósticos de íleo meconial (90\%) é relativa à fibrose cística. Portanto, devese ressaltar a importância de tratar todo paciente com íleo meconial como fibrose cística até prova em contrário. Outra manifestação que pode ocorrer ainda no período neonatal, em cerca de 5\% dos fibrose cística, é edema hipoproteinêmico secundário à $\mathrm{IP}^{5}$.

O tecido endócrino do pâncreas é preservado inicialmente, mas com o aumento da idade do paciente, células são perdidas e a glândula começa a ser completamente substituída por tecido fibroso e gordura ${ }^{30}$. Quando o comprometimento atinge a porção endócrina do pâncreas, pode ocorrer intolerância a glicose e diabetes mellitus. Isto ocorre em $8 \%$ a $15 \%$ dos pacientes, podendo aumentar com a idade ${ }^{31}$. O diabetes, por sua vez, pode aumentar as perdas energéticas como um resultado da glicosúria ${ }^{32}$, porém para Ward et al. ${ }^{33}$ não há muita diferença de necessidade de energia entre os grupos fibrocísticos diabéticos e não diabéticos, em ambos os casos as necessidades estão aumentadas devido à doença, o cuidado com o paciente diabético é que deve ser maior.

Estudos estimam que o predomínio de diabetes mellitus em pacientes com fibrose cística varia de $2,5 \%$ a $12,0 \%$, aumentando consideravelmente com a idade. Na Dinamarca, 32,0\% dos pacientes com fibrose cística desenvolveram diabetes mellitus por volta dos 25 anos de idade. Isto, obviamente, tem importância nutricional considerável. A causa primária é a deficiência de insulina, mas também é influenciada por condições raras na fibrose cística, como desnutrição, infecções aguda e crônica, gasto elevado de energia, deficiência de glucagon, má absorção, tempo de trânsito intestinal anormal, multiplicação bacteriana excessiva e disfunção hepática, tudo influenciando a intolerância à glicose ${ }^{34}$.

Outra manifestação comum nos fibrocísticos é a síndrome de obstrução intestinal distal (DIOS), caracterizada pelo bloqueio parcial ou completo do intestino, podendo ocorrer cólicas, dor e/ou distensão abdominal e anorexia. O refluxo gastroesofágico ocorre com maior freqüência nos pacientes com fibrose cística e está diretamente relacionado com o desenvolvimento da doença respiratória severa ${ }^{35}$.

\section{Manifestações hepáticas}

Com o aumento da sobrevida dos pacientes com fibrose cística, as manifestações hepatobiliares da doença têm se tornado um desafio diagnóstico e terapêutico. Tendo por base apenas critérios clínicos, a hepatopatia é encontrada em $1,4 \%$ a $7,0 \%$ dos pacientes fibrocísticos ${ }^{36}$. No entanto, quando indicadores bioquímicos e ultrasonográficos são incluídos, a prevalência aumenta 
significativamente, e quanto mais precoce a identificação, melhor a resposta do paciente em relação aos com cirrose avançada ${ }^{37}$.

O metabolismo alterado dos sais biliares favorece a formação de cálculos biliares em, aproximadamente, $12 \%-15 \%$ dos pacientes fibrocísticos. A cirrose hepática ocorre em, aproximadamente, $5 \%$ dos pacientes, sendo a retenção de sais biliares hepatotóxicos um fator contribuinte para o aparecimento da doença hepática ${ }^{38}$.

A lesão hepática acarreta danos na síntese endógena de vitamina $D$ e de seus metabólitos, podendo resultar em doença óssea e alterações no metabolismo do cálcio, sendo que a absorção intestinal desse mineral se faz sob a influência da vitamina D. Os baixos níveis séricos de $25(\mathrm{OH})$ vitamina $\mathrm{D}$ contribuem para liberação do paratormônio (PTH) com o objetivo de elevar a calcemia, porém altos níveis desse hormônio mobiliza cálcio e fósforo dos ossos, diminuindo ainda mais a massa óssea ${ }^{39}$

Uma das complicações mais significativas é a perda de massa óssea, aumentando o risco de fraturas, tanto de vértebras como de colo de fêmur. Entre os fatores relacionados à diminuição de massa óssea, estão o baixo índice de massa corporal, a menor prática de atividade física, o uso de glicocorticóides devido à lesão pulmonar, uma menor formação da massa óssea na infância e adolescência, a gravidade da doença, o hipogonadismo, o aumento de citocinas inflamatórias e distúrbios no metabolismo do cálcio ${ }^{40}$.

\section{Tratamento}

O tratamento pré-sintomático ainda é o mais indicado para pacientes com fibrose cística, e tem como objetivos adiar as infecções pulmonares, bem como controlar as deficiências enzimáticas. Embora grandes avanços tenham sido alcançados, o tratamento da fibrose cística por meio da terapia genética, para recuperar a expressão correta do gene ou que regule o sistema de transporte de íons, é ainda experimental ${ }^{20}$.
No tratamento da fibrose cística, vários medicamentos (antibióticos, anti-inflamatórios, broncodilatadores, mucolíticos) ou procedimentos (fisioterapia respiratória, oxigenioterapia, transplante de pulmão, reposição de enzimas digestórias, suporte nutricional, suporte psicológico e de social, terapia gênica) podem ser necessários ${ }^{5}$, incluindo uma equipe multidisciplinar de profissionais ${ }^{41}$. Além do tratamento medicamentoso e de outros procedimentos clínicos, o cuidado da família é essencial, e já mostrou trazer benefícios para os pacientes ${ }^{42}$, também é importante que estejam sempre bem informados sobre a doença ${ }^{6}$.

Uma vez que esta doença é freqüentemente subdiagnosticada, quando não são realizados estudos de triagem neonatal, e tem caráter crônico com variados graus de manifestações clínicas e requer continuamente o uso de medicamentos, assim como de assistência multidisciplinar, o custo médio do tratamento é elevado e difícil de ser estimado. Por este motivo, independentemente da renda familiar, os fibrocísticos e suas famílias têm garantido o direito de receber assistência do governo, via Sistema único de Saúde (SUS), ao qual compete o diagnóstico precoce, por meio do teste do pezinho, até o fornecimento de suplementos alimentares, enzimas digestórias e medicamentos.

Em Minas Gerais, a resolução SES n 1088 , de 29 de dezembro de $2006^{43}$, instituiu a Rede Estadual de Atenção à Saúde do Portador de Fibrose Cística, composta por Centros de Referência para Assistência Integral ao Portador de Fibrose Cística (CRFC). Para assegurar essa assistência, o CRFC deverá ser estruturado em unidades de saúde com atendimento ambulatorial, serviços de pronto atendimento e internação, que disponham de serviços de infectologia, nutrição clínica e assistência farmacêutica e que tenham capacidade para realizar exames de doença clínica, microbiologia, imagens e provas de função pulmonar, dentro das necessidades específicas do protocolo assistencial. O CRFC deverá contar obrigatoriamente com equipes constituídas por médicos especializados em pneumologia e gastroen- 
terologista, enfermeiro, fisioterapeuta respiratório, nutricionista, assistente social e psicólogo.

Além das dificuldades enfrentadas pelos fibrocísticos no dia-a-dia, ainda há o problema do custo do tratamento. O tratamento inicial dos portadores da fibrose cística na rede particular custa entre $R \$ 2$ mil a $R \$ 10$ mil, dependendo do grau de comprometimento da doença. Os valores são justificativas para muitos estados ainda não incluírem o diagnóstico dessa enfermidade no teste do pezinho, apesar de previsto em Portaria do Ministério da Saúde. Apenas Minas, Paraná, Santa Catarina e Rio de Janeiro realizam os testes. "O custo do tratamento pode fazer o gestor marginalizar a discussão, já que os recursos para a saúde pública são escassos. No entanto, não se pode pensar desta forma, pois o SUS não deve discriminar ninguém ${ }^{44}$. As famílias de baixo poder aquisitivo não tem como manter esse tratamento visto que a doença é por toda a vida, e para tratála é necessária a atuação de vários profissionais, desse modo é fundamental que o SUS banque o tratamento para uma melhor expectativa de vida dos fibrocísticos.

Outra dificuldade com relação à doença é a aceitação desta e a participação da família no tratamento. De acordo com depoimento de uma mãe, disponível no sitio "Fibrose Cística: Tudo sobre esta doença" ${ }^{45}$, conviver com essa doença crônica progressiva, induz os familiares a ultrapassar certos estágios de aceitação e enfrentamento, que vão surgindo com o tempo, e que podem tornar-se, inclusive, decisivos no estado clínico e psicológico do paciente. O primeiro estágio está no diagnóstico, é o momento no qual a doença é apresentada com uma bagagem de orientações que poderão ocasionar negações, culpas e muitos questionamentos. Um bom suporte de apoio nessa fase é essencial à família, para que se recupere das dificuldades de aceitação, e assimile a importância do tratamento continuo, e da responsabilidade de todos perante o mesmo.

Outro estágio está exatamente na busca de conhecimento, momento em que geralmente a família procura compreender o que é a doença, e o que se passa com o metabolismo do indivíduo que a possui, esse é o momento de comparar sintomas vividos com as descrições cientificas encontradas em literaturas e nas explicações médicas sobre a mesma ${ }^{45}$.

Os significados vão sendo compartilhados entre pais, pacientes e profissionais, e assim, os desafios vão sendo conquistados na medida em que vão surgindo. Importante é perceber quando esses problemas surgem, e juntamente com a equipe multidisciplinar buscar a melhor maneira de amenizar as diversas situações ${ }^{45}$.

As internações e consultas freqüentes, também muitas vezes podem gerar conflitos inter-nos e familiares, mas que geralmente são assimilados como necessários para o acompanhamento e bem estar do paciente. Neste momento quanto maior a interação e envolvimento da família ao tratamento, maior será a própria aceitação do paciente. Importante é estimular desde cedo, a busca de planos e objetivos de vida, de satisfação pessoal, como a escola, que deverá ser vivida normalmente, assim como mais adiante a carreira profissional ${ }^{45}$.

E quando a família passa a se identificar no plural, evidentemente que mais um estágio foi alcançado e, com ele, o amadurecimento e a consciência da doença e a importância do tratamento. Esses estágios podem ser duradouros ou momentâneos, porque a medicina se responsabiliza pelo tratamento, mas o viver na doença é uma construção de cada individuo, de cada lar, é como se cada dia se reaprendesse a viver, construindo modos diferentes de sentir. Assim, essencial é não entender a Fibrose Cística como um obstáculo, mas como um futuro a ser conquis$\operatorname{tado}^{45}$.

\section{Tratamento nutricional}

Os problemas nutricionais e as conseqüências da fibrose cística são multifatoriais e relacionadas com a progressão da doença. Fatores interdependentes, como deterioração da função pulmonar, anorexia, vômitos, insuficiência pan- 
creática e complicações biliares e intestinais são responsáveis pelo aumento das necessidades energéticas, ingestão diminuída e aumento das perdas atribuídas à inadequação nutricional, com conseqüente perda da massa magra e depressão da função imunológica ${ }^{30}$.

A meta do tratamento nutricional é alcançar e manter o peso ideal para a altura, aumentar e equilibrar a ingestão energética, reduzir a má absorção e má digestão e controlar a ingestão de vitaminas e minerais ${ }^{22}$. Para tanto, o cuidado nutricional adequado deve incluir: terapia de reposição enzimática, dietas hiperenergéticas e hiperlipídicas, e suplementação de micronutrientes ${ }^{28}$.

Em relação à terapia de reposição enzimática, Wood et al. ${ }^{28}$ citam que a suplementação enzimática deve ser individualizada, evitando a oferta insuficiente que leva à desnutrição e a excessiva, que causa complicações intestinais, como a colonopatia fibrosante. Segundo estes mesmos autores, a quantidade ideal deve ser ajustada pelo médico em conjunto com a família, de acordo com o ganho de peso, número de evacuações e característica das fezes do fibrocístico.

No Brasil, as recomendações para o tratamento de reposição enzimática estão explícitas na Portaria n. 263, de 18 de julho de 200146, que preconiza o início do tratamento com $1000 \mathrm{U} / \mathrm{kg} /$ refeições de lipase para menores de 4 anos e $500 U / \mathrm{kg} /$ refeição para maiores de 4 anos e, usualmente, metade da dose deve ser utilizada após a ingestão de lanches. A dose total deve ser suficiente para 3 refeições e 2 a 3 lanches. Se sinais e sintomas de má-absorção persistem, incrementos nas doses podem ser realizados. Não se sabe a segurança de doses entre 2500 a 6000 U/kg/refeição; acima dessa dose o risco de colonopatia fibrosante tem sido descrito. No caso do desenvolvimento de colonopatia, a dose deve ser reduzida para 500 a $2500 \mathrm{U} / \mathrm{kg} /$ refeição. Ainda, segundo Hutchison et al., citado por Brasil ${ }^{46}$, o uso de antiácidos é recomendado para pacientes portadores de fibrose cística, em uso destas enzimas, por aumentar a biodisponibilidade das enzimas é por diminuir a inativação pelo pH baixo.
Apresentações com elevadas concentrações de lipase parecem ter a mesma eficácia que apresentações de baixa concentração, porém não são recomendadas para crianças com menos de 15 anos. Dose máxima diária não deve ultrapassar 10 000U/kg de lipase; caso não se consiga controle adequado dos sintomas, doses maiores poderão ser utilizadas após a avaliação por comitê de especialistas nomeados pelo Gestor Estadual ${ }^{47}$.

Com relação às necessidades energéticas, Dowsett ${ }^{22}$ cita que para compensar as carências comuns aos fibrocísticos, o tratamento nutricional deve incluir uma recomendação de ingestão para gênero e idade de $120 \%$ a $150 \%$ das necessidades diárias recomendadas (RDA) para energia. Outros autores ${ }^{28,47}$ afirmam que, em relação à recomendação de lipídeos, estes devem corresponder a $40 \%$ da distribuição energética total diária, enquanto que as proteínas devem suprir de 150\% a $200 \%$ da RDA. Ainda, segundo MaCDonald ${ }^{48}$, a ingestão diária carboidratos deve ser em torno de $40 \%$ a $50 \%$ do valor energético total da dieta.

Caso o paciente não consiga ingerir todo o volume energético recomendado é importante fazer uso de suplementos energéticos juntamente com a terapia de reposição enzimática ${ }^{49}$.

A suplementação de vitaminas e minerais faz parte da terapia nutricional. As vitaminas hidrossolúveis são bem absorvidas nos fibrocísticos, embora a vitamina B12 precise ser suplementada em pacientes com ressecção do íleo ${ }^{50}$. Já as lipossolúveis são pouco absorvidas, devido à máabsorção de gorduras ${ }^{51}$. Para fazer uma adequada reposição desses nutrientes é importante realizar exames sangüíneos freqüentes para identificar qual a real necessidade de suplementação ${ }^{49,50}$. A maioria dos pacientes está em risco de desenvolver deficiências subclínicas de várias vitaminas lipossolúveis, dentre eles estão os que apresentam má absorção, os que apresentam baixa adesão ao tratamento, doença hepática, ressecção intestinal, ou o atraso no diagnóstico 22,28 .

A deficiência da vitamina A nos fibrocísticos é comum, e níveis baixos desse nutriente pode persistir, apesar da terapia de reposição enzimática 
e de suplementação. Esses pacientes estão com risco maior de desenvolverem hipovitaminose $A$, porque além da má-absorção ainda existe o estresse inflamatório da doença pulmonar e lesão hepática. No entanto, observa-se maior reserva hepática desse nutriente nestes indivíduos, quando comparados com pessoas hígidas, o que indica um fracasso no transporte ou, mobilização da vitamina A do fígado para os tecidos, ou seja, pode indicar uma deficiência na proteína carreadora de retinol $(P C R)$, e isso é tão grave quanto as infecções, má-absorção e a própria deficiência de vitamina $A^{22,28}$.

Segundo Sinaappel et al. ${ }^{34}$ e MacDonald ${ }^{48}$, a ingestão de vitamina $A$ deve ser elevada o suficiente para alcançar a concentração sérica normal sem provocar efeitos colaterais, geralmente empregando-se doses diárias, que variam

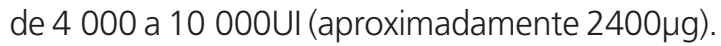

Reiter et al. ${ }^{52}$ encontraram baixos níveis de metabólitos de vitamina $D$ em pacientes fibrocísticos, apesar de receberem 1 000Ul de vitamina $\mathrm{D}$ por dia, provavelmente associada à reduzida exposição solar. Thompson ${ }^{53}$ demonstrou que pacientes com fibrose cística tinham menor nível de vitamina $D$ no inverno que no verão. $A$ deficiência desta vitamina tem sido associada ao decréscimo na densidade mineral óssea e osteopenia, demonstrando decréscimo nos níveis de cálcio (Ca) e fósforo $(P)^{28}$.

MacDonald ${ }^{48}$ e Vieth ${ }^{54}$ citam que, para manter os níveis sangüíneos adequados de vitamina $D$, é recomenda uma dose diária de 400

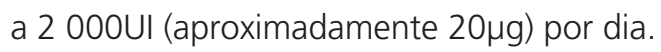

Em estudo desenvolvido por WinklhoferRoob et al. ${ }^{55}$ foi observado que $45 \%$ dos pacientes suplementados com vitamina $\mathrm{E}$ apresentaram baixos níveis plasmáticos desse nutriente, enquanto $87 \%$ dos pacientes não suplementados eram deficientes. Similarmente, $17 \%$ dos pacientes suplementados apresentaram deficiência em vitamina E eritrocítica, enquanto $50 \%$ dos pacientes não suplementados estavam deficientes.

Assim, MacDonald ${ }^{48}$ e Vieth ${ }^{56}$ afirmam que a suplementação de vitamina E deve ser recomen- dada, com doses diárias de 50mg até 1 ano de idade, $100 \mathrm{mg}$ entre 1 a 10 anos, e $200 \mathrm{mg}$ para adolescentes e adultos.

Os fatores de risco para desenvolver deficiência de vitamina $\mathrm{K}$ em fibrocísticos são insuficiência pancreática, doença hepática, ressecção intestinal, e antibioticoterapia. A suplementação dessa vitamina pode ser recomendada, porém não há consenso sobre a dose diária22, 48 .

Níveis reduzidos de zinco, selênio, cobre e ferro são descritos na fibrose cística. Porém a suplementação com ferro não é recomendada, devido à formação de radicais livres e ao aumento do crescimento da bactéria P. aeruginosa ${ }^{22}$. O zinco é um elemento importante na composição de muitas enzimas, podendo tornar-se deficiente devido à má-absorção de gorduras em pacientes com fibrose cística, pois forma complexos com a gordura e o fósforo ${ }^{56}$.

As crianças fibrocísticas podem perder sal na forma de cloreto de sódio, especialmente em clima quente, ou quando estiver presente febre e/ou diarréia, sendo necessário suplementar 2-4 $\mathrm{mmol} / \mathrm{kg} / \mathrm{dia}$ de cloreto de sódio ${ }^{50}$.

\section{CONSIDERAÇÕ ES FINAIS}

Pode-se perceber que, nos últimos anos, houve um aumento da sobrevida dos pacientes fibrocísticos, devido às pesquisas e aos avanços científicos que possibilitaram um melhor conhecimento da doença, bem como à inclusão da dosagem da tripsina imunorreativa (IRT) na triagem neonatal, permitindo o diagnóstico precoce da doença e a implantação de tratamento multidisciplinar visando à prevenção da desnutrição e da deterioração da função pulmonar. Além disso, o desenvolvimento de estudos com relação à terapia gênica e às células-tronco pode gerar muitos benefícios no tratamento dos pacientes.

Contudo, há poucos estudos clínicos que avaliam as necessidades nutricionais ideais para os fibrocísticos. As recomendações atuais de ingestão diária são baseadas no quadro patológico de 
infecção e de má absorção, assim como é recomendado para qualquer paciente com essas disfunções. O uso de proteases e outras enzimas, como a amilase pancreática, também precisa ser melhor avaliado, pois na literatura só há relatos da suplementação com lipases.

Além dos cuidados com a alimentação do fibrocístico, o vínculo entre pais e filhos portadores deste problema deve ser estimulado. Os pais devem ser informados sobre a doença, os cuidados especiais que ela exige e a importância da adesão ao tratamento, para a melhor qualidade de vida do paciente.

Finalmente, é importante que todos os estados brasileiros sigam o exemplo de Minas Gerais, Paraná, Santa Catarina e Rio de Janeiro, e passem a incluir o diagnóstico dessa enfermidade no teste do pezinho, pois a formulação de uma política pública direcionada a esses pacientes somente será possível a partir do momento em que se conheça a real prevalência dessa doença.

A partir desse conhecimento é inquestionavelmente necessário assegurar a criação de centros especializados para tratamento do fibrocístico, para dar melhor suporte ao paciente e à sua família, assegurar o custeio do tratamento e, sobretudo, garantir resultados mais significativos na evolução do tratamento e uma maior expectativa de sobrevida dos pacientes.

\section{COLABORADORES}

F.R. ROSA e F.G. DIAS foram responsáveis pelo levantamento bibliográfico e pela redação do artigo. L.N.NOBRE e H.A. MORAIS orientaram o trabalho e contribuíram com a redação deste artigo.

\section{REFERÊ NCIAS}

1. Lyczak JB, Cannon CL, Pier GB. Lung infections associated with cystic fibrosis. Clin Microbiol Rev. 2002; 15(2):194-222.

2. Bentley P. Undeerstanding cystic fibrosis, improving life expectancy. Nurs Times. 1999; 95(43):50-61.

3. Morison S, Dodge JA, Cole TJ, Lewis PA, Coles EC, Geddes $D$, et al. Height and weight in cystic fibrosis: a cross sectional study. Arch Dis Child. 1997; 77(6): 427-500.

4. Adde FV, Rodrigues JC, Cardoso AL. Seguimento nutricional de pacientes com fibrose cística: papel do aconselhamento nutricional. J Ped. 2004; 80(6):475-82.

5. Ribeiro JD, Ribeiro MAGO, Ribeiro AF. Controvérsias na fibrose cística: do pediatra ao especialista. J Ped. 2002; 78(supl.2):171-86.

6. Balinsky W, Zhu CW. Pediatric cystic fibrosis: evaluating cost and genetic testing. J Pediatr Health Care. 2004; 18(1):30-4.

7. Pereira L, Raskin S, Freund AA, Ribas PD, Castro RMV, Pignatti PF, et al. Cystic fibrosis mutations R1162X and 2183AA! in two Southern Brazilian states. Genet Mol Biol. 1999; 22(3):291-4.

8. Raskin S, Philips JA, Krishnamani MR, VnencakJones C, Parler RA, Dawson E, et al. Regional distributions of cystic fibrosis-linked DNA halotypes in Brazil: multicenter study. Hum Biol. 1997; 69(1):75-8.

9. Collins CE, MacDonald-Wicks L, Rowe $S$, O'Loughlin EV, Henry RL. Normal growth in cystic fibrosis associated with a specialized center. Arch Dis Child. 1999; 81(3):241-6.

10. Mickie JE, Cutting GR. Clinical implications of cystic fibrosis transmembrane conduntance regulator mutations. Clin Chest Med. 1998; 19(3):443-58.

11. Fiates GMR, Barbosa E, Auler F, Feiten SF, Miranda F. Estado nutricional e ingestão alimentar de pessoas com fibrose cística. Rev Nut. 2001; 14(2):95-101.

12. Lemos AC, Matos E, Franco R, Santana P, Santana MA. Fibrose cística em adultos: aspectos clínicos e espirométricos. J Bras Pneumol. 2004; 30(1):9-13.

13. Brasil. Portaria SAS/MS n ${ }^{\circ} 338$ de 29 de junho de 2005. Brasília; 2005 [acesso 2007 ago 15]. Disponível em: <http://dtr2001.saude.gov.br/sas/ PORTARIAS/Port2005/PT-338.htm>.

14. Helms PJ. Growing up with cystic fibrosis. Br J Hosp Med. 1998; 50(6):326-32.

15. Reis FJC, Oliveira MCL, Penna FJ, Oliveira MGR, Oliveira EA, Monteiro APAF. Quadro clínico e nutricional de pacientes com fibrose cística: 20 anos de seguimento no HC-UFMG. Rev Assoc Med Brasil. 2000; 46(4):325-30.

16. Fibrose cistica: tudo sobre esta patologia [acesso 2008 maio 31]. Disponível em: <http://www. fibrosecistica.com/fibrose-cistica-prognostico. html>.

17. Alvarez A, Ribeiro AF, Hessel G, Bertuzzo CS, Ribeiro JD. Fibrose cística em um centro de referência no Brasil: características clínicas e laboratoriais de 104 
pacientes e sua associação com o genótipo e a gravidade da doença. J Ped. 2004; 80(5):371-9.

17. Camargos PAM, Guimarães MDC, Reis FC. Prognostic aspects of cystic fibrosis in Brazil. Ann Trop Pediatr. 2000; 20(4):287-91.

18. Green MR, Buchanan E, Weaver LT. Nutritional management of the infant with cystic fibrosis. Arch Dis Child. 1995; 72(5):452-6.

19. Cabello GMK, Cabello PH, Roig SRS, Fonseca A, Carvalho ECD, Fernandes O. Rastreamento da fibrose cística usando-se a análise combinada do teste de IRT neonatal e o estudo molecular da mutação DF508. J Bras Patol Med Lab. 2003; 39(1): 15-20.

20. Silva Filho LVF, Bussamra MHCF, Nakaie CMA. Fibrose cística com dosagem de cloro no suor normal: relato de caso. Rev Hosp Clin. 2003; 58(5): 260-2.

21. Dowsett J. An overview of nutritional issues for the adult with cystic fibrosis. Nutrition. 2000; 16(7/ 8):566-70.

22. Dallalana LT. Fibrose cística. In: Tarantino AB. Doenças pulmonares. 5a. ed. São Paulo: Guanabara Koogan; 2002. p.624-40.

23. Andrade EF, Fonseca DLO, Silva FAA, Menna-Barreto SS. Avaliação evolutiva da espirometria na fibrose cística. J Bras Pneum. 2001; 27(3):130-6.

24. Magalhães $M$, Britto MCA, Becerra PGM, Veras A. Prevalência de bactérias potencialmente patogênicas em espécimes respiratórias de fibrocístico do Recife. J Bras Pat Med Lab. 2004; 40(4):223-7.

25. Raymond NC, Chang PN, Crow SJ, Mitchell JE, Dieperink BS, Beck MM, et al. Eating disorders in patients with cystic fibrosis. J Adolesc. 2000; 23(3): 359-63.

26. Evans AK, Fitzgerald DA, Mckay KO. The impact of meconium ileus on the clinical course of children with cystic fibrosis. Eur Respir J. 2001; 18(5):784-9.

27. Wood LG, Gibson PG, Garg ML. Circulating markers to assess nutritional therapy in cystic fibrosis. Clin Chim Acta. 2005; 353(1/2):13-29.

28. Kalivianakis $M$, Minich DM, Bijleveld $C M$, van Aalderen WM, Stellaard F, Laseur M, et al. Fat malabsorption in cystic fibrosis receiving enzyme replacement therapy is due to impaired intestinal uptake of long chain fatty acids. Am J Clin Nutr. 1999; 69(1):127-34.

29. Creveling S, Light M, Gardner P, Greene L. Cystic fibrosis, nutrition, and the health care team. J Am Diet Assoc. 1997; 97(10 Suppl 2):S186-91.

30. Donald AM. Nutritional management of cystic fibrosis. Arch Dis Child. 1996; 74(1):81-7.
31. Ramsey BW, Farrell PM, Pencharz P. Nutritional assessment and management in cystic fibrosis: a consensus report. Am J Clin Nut. 1992; 55(1): 108-16.

32. Ward SA, Tomezsko JL, Holsclaw DS, Paolone AM. Energy expenditure and substrate utilization in adults with cystic fibrosis and diabetes mellitus. Am J Clin Nutr. 1999; 69(5):913-9.

33. Sinaasappel M, Stern M, Littlewood J, Wolfe S, Steinkamp G, Heijerman HGM, et al. Nutrition in patients with cystic fibrisis: a European Consensus. J Cyst Fibros. 2002; 1(2):51-75.

34. Burdet L, Hugli O, Aubert JD, Schutz Y, Roulet M, Fitting JW. Effect of elective antibiotic therapy on resting energy expenditure and infection in patients with cystic fibrosis. Eur J Pediatr. 1999; 158(9):711-6.

35. Fagundes EDT, Silva RAP, Roquete MLV, Penna FJ, Reis FJC, Goulart EMA, et al. Validação do escore ultra-sonográfico de Williams para o diagnóstico da hepatopatia da fibrose cística. J Pediatr (Rio de Janeiro). 2004; 80(5):380-6.

36. Sokol RJ, Durie PR. Recommendations for managment of liver and biliary tract disease in cystic fibrosis. J Pediatr Gastroenterol Nutr. 1999; 28(Suppl 1):S1-13.

37. Hamer L, Parker HW. Treatment of cystic fibrosis in adults. Am Fam Physician. 1996; 54(4):1291-7.

38. Moreira RO, Duarte MPC, Farias MLF. Distúrbios do eixo cálcio-PTH-vitamina D nas doenças hepáticas crônicas. Arq Bras End Met. 2004; 48(4): 443-50.

39. Elkin SL, Fairney A, Burnett S, Kemp M, Kyd P, Burgess J, et al. Vertebral deformities and low bone mineral density in adults with cystic fibrosis: a crosssectional study. Osteoporos Int. 2001; 12(5): 366-72.

40. Allison JLS. Management of adolescent and adult inpatients with cystic fibrosis. Am J Health Syst Pharm. 1999; 56(2):158-60.

41. Richardson I, Nyulasi I, Cameron K, Ball M, Wilson J. Nutritional status of an adult cystic fibrosis population. Nutrition. 2000; 16(4):255-9.

42. Minas Gerais. Resolução SES n 1088 de 29 de dezembro de 2006. Institui a Rede Estadual de Atenção à Saúde do Portador de Fibrose Cística. Belo Horizonte; 2006 [acesso 2007 ago 15]. Disponível em: <http:// www.saude.mg.gov.br/ atos_normativos/resolucoes/2006>.

43. Conselho Nacional de Secretaria da Saúde de Minas Gerais. SES/MG - Minas busca diagnosticar pessoas que não sabem que tem doença rara [acesso 2008 maio 31]. Disponível em: <http:// www.conass.org.br/?page=noticias_estados\& 
codigo $=1761 \& \mathrm{i}=0 \&$ mesAtual $=04 \&$ anoAtual $=2006$ \&diaAtual=06>.

44. Vivendo com a fibrose cística. [acesso 31 maio 2008]. Disponível em: <http://www.gbefibrose cística.org.br/>.

45. Brasil. SAS/MS n 263, de 18 de julho de 2001. Fibrose cística: enzimas pancreáticas. Brasília; 2001 [acesso 2005 jul]. Disponível em: <http://www. saude.gov.br>.

46. Sharma $M$, Singh $M$. Nutritional management of children with cystic fibrosis. Ind Ped. 2003; 40(11): 1055-62.

47. MacDonald A. The diet in cystic fibrosis: why is it important? Curr Paed. 2000; 10(3):155-61.

48. Koletzko S, Reinhardt D. Nutritional challenges of infants with cystic fibrosis. Early Hum Dev. 2001; 65(Suppl 2):S53-61.

49. Wilson DC, Pencharz PB. Nutrition and cystic fibrosis. Nutrition. 1998; 14(10):792-3.

50. Feranchak AP, Sontag MK, Wagener JS, Hammond KB, Accurso FJ, Sokol RJ. Prospective long-term study of fat-soluble vitamin status in children with cystic fibrosis diagnosed by newborn screen. J Pediatr. 1999; 135(5):601-10.
51. Reiter EO, Brugman SM, Pike JW, Pitt M, Dokoh S, Haussler MR, et al. Vitamin D metabolites in adolescents and young adults with cystic fibrosis: effects of sun and season. J Pediatr. 1985; 106(1): 21-6.

52. Thompson GN. Determinants of serum vitamin D levels in preadolescent cystic fibrosis children. Acta Paediatr Scand. 1987; 76(6):962-5.

53. Vieth R. Problems with direct 25-hidroxyvitamin D assays, and the target amount of vitamin D nutrition desirable for patients with osteoporosis. Osteoporos Int. 2000; 11(7):553-5.

54. Winklhofer-Roob BM, van't Hof MA, Shmerling $\mathrm{DH}$. Long-term oral vitamin $\mathrm{E}$ supplementation in cystic fibrosis patients: RRR-alpha-tocopherol compared with all-rac-alpha-tocopheryl acetate preparations. Am J Clin Nutr. 1996; 63(5):722-8.

55. Easley D, Krebs N, Jefferson M, Miller L, Erskine J, Accurso $F$, et al. Effect of pancreatic enzyme on zinc absorption in cystic fibrosis. J Pediatr Gastroenterol Nutr. 1998; 26(2):136-9.

Recebido em: 17/5/2006

Versão final reapresentada em: 3/6/2008 Aprovado em: 8/8/2008 